\title{
Kernos
}

Revue internationale et pluridisciplinaire de religion grecque antique

30 | 2017

Varia

\section{Exercices d'histoire des religions : Comparaisons, rites, mythes et émotions}

\section{Elie Piette}

\section{(2) OpenEdition \\ Journals}

\section{Édition électronique}

URL : http://journals.openedition.org/kernos/2553

DOI : 10.4000/kernos.2553

ISSN : 2034-7871

\section{Éditeur}

Centre international d'étude de la religion grecque antique

\section{Édition imprimée}

Date de publication : 1 octobre 2017

Pagination : 364

ISSN : 0776-3824

\section{Référence électronique}

Elie Piette, «Exercices d'histoire des religions : Comparaisons, rites, mythes et émotions », Kernos [En ligne], 30 | 2017, mis en ligne le 01 octobre 2017, consulté le 24 septembre 2020. URL : http:// journals.openedition.org/kernos/2553 ; DOI : https://doi.org/10.4000/kernos.2553

Ce document a été généré automatiquement le 24 septembre 2020.

Kernos 


\title{
Exercices d'histoire des religions : Comparaisons, rites, mythes et émotions
}

\author{
Elie Piette
}

\section{RÉFÉRENCE}

Philippe BORGEAUD, Exercices d'histoire des religions : Comparaisons, rites, mythes et émotions, édité par Daniel Barbu et Philippe Matthey, Leiden/Boston, Brill, 2016.1 vol. $16 \times 24 \mathrm{~cm}$, XVII+362 p. (Jerusalem Studies in Religion and Culture, 20). ISBN : 978-90-0431-632-4.

1 Cet ouvrage rassemble des publications de Philippe Borgeaud, professeur ordinaire d'histoire des religions antiques à l'Université de Genève aujourd'hui retraité. Le titre fait écho aux Exercices de mythologie du même auteur qui, en 2004, transmettait ses réflexions sur le mythe. La matière envisagée dans le présent volume est néanmoins plus variée que celle des Exercices de 2004. Après l'introduction de D. Barbu et Ph. Matthey qui retracent notamment son parcours, dix-neuf articles en français sont rassemblés sous deux intitulés : "Comparaison et histoire des religions» et "Rite, mythe et émotion». Ces contributions ont paru dans différents ouvrages et revues entre 1986 et 2011, à l'exception d'un texte inédit, consacré à la figure de J.-P. Vernant et à son impact sur la religion grecque et, plus largement, sur l'histoire des religions.

2 L'ouvrage dévoile les étapes d'une pensée qui se construit, qui s'affine tout au long de ces exercices. Des concepts tels que « religion », «sacré », « croyance » ou " dogme » traversent le livre, non sans un certain nombre de reprises et de redondances. L'accent est également mis sur quelques aspects primordiaux pour l'A., tels que le travail en équipe, inévitable aujourd'hui dans une approche comparatiste. Pour reprendre son image (p. 157), le comparatisme est ce besoin du spécialiste « d'ouvrir son terrain de chasse aux braconniers que sont les collègues des champs d'alentour, et de se faire braconnier lui aussi ». 
3 La comparaison est en effet le leitmotiv, le fil conducteur de la première partie, voire $\mathrm{du}$ livre entier. Sans cet outil fondamental, déjà pratiqué par Lafitau au $\mathrm{XVIII}^{\mathrm{e}}$ siècle entre les Iroquois et le monde classique, il n'y aurait pas d'histoire des religions. Attention toutefois aux dangers d'un comparatisme tous azimuts, contre lequel l'A. met aussi en garde. Ces premiers articles contiennent, plus largement, une réflexion sur les outils et les méthodes d'une discipline qui cherche toujours sa définition : l'historien des religions doit de fait «observer, décrire, comparer» (p. 159). Cette partie pourrait être plus particulièrement définie comme une histoire de l'histoire des religions. Les grandes figures que sont Max Müller, Otto, Eliade, Frazer ou encore Durkheim, pour ne citer qu'une partie des auteurs convoqués, apparaissent et réapparaissent tout au long de ces onze chapitres, avec leurs apports à la discipline ainsi que leurs limites. L'A. souligne également les liens étroits avec la philologie, la sociologie, l'anthropologie, l'ethnologie, ou encore la psychologie. Ce premier ensemble de textes se clôture par sa leçon d'adieu à l'Université de Genève, qui synthétise un ensemble de considérations abordées précédemment.

4 Le second ensemble puise dans les considérations théoriques développées dans la première partie, toujours dans une optique comparatiste. L'ouvrage est ainsi conçu comme un diptyque, dans lequel les deux ensembles se retrouvent séparés, mais sont irrémédiablement liés. L'A. fournit quelques exemples pratiques de comparaison en histoire des religions, sur des sujets tels que les interdits alimentaires, le parfum ou la langue des dieux. Le matériau est principalement grec et romain, mais l'A. ne cesse d'intégrer d'autres cultures, notamment égyptiennes, conformément à son optique comparatiste. Les enquêtes sur l'articulation de l'affect au rite et au mythe sont le fruit d'un projet de recherche sur le mythe en tant qu'expression culturelle des émotions, mené à Genève entre 2005 et 2011. "L'anthropologie des émotions" est utile pour comprendre le fonctionnement des mystères dans le monde grec ainsi que pour cerner la perception des dieux. Cette dernière est teintée de crainte, mais une crainte particulière que la langue française peine à rendre fidèlement. Dans cette recherche interviennent à nouveau les notions de religio et de superstitio ou, en grec, de deisidaimonia, de "peur des dieux». Un autre concept, celui de l'interpretatio, est également abordé et montre que la pratique de la comparaison n'était pas ignorée des Grecs et des Romains eux-mêmes, notamment vis-à-vis de la tradition égyptienne. Cette comparaison ne s'apparente toutefois pas à une assimilation: elle compare tout en distinguant, elle établit une hiérarchie. Les notions de « Même » et d' "Autre » sont dès lors interrogées. De même que dans la première partie, un article, publié en 2009 dans le supplément 21 de Kernos, clôture la réflexion sur le rite, le mythe et l'émotion en en retraçant les lignes directrices.

5 L'A. intervient aussi dans les débats contemporains, où sa volonté de ne pas confondre religion et moralité est manifeste. À plusieurs reprises, son discours apparaît comme engagé, face à des problématiques liées au "désenchantement du monde " et à la " désécularisation ». Si l'ouvrage s'avère être un compagnon adéquat pour appréhender les grandes figures qui ont façonné l'histoire des religions ainsi que pour appréhender des concepts essentiels de la religion grecque que sont le sacré, le mythe ou la perception des dieux, il rappelle également quel rôle y a tenu l'A., qui a soutenu l'importance d'une étude critique, historique et attentive à l'écueil de l'ethnocentrisme, voire du monothéocentrisme. En retraçant l'évolution de cette discipline, il montre le chemin à suivre, les obstacles sur la route ainsi que les moyens de les éviter. 


\section{AUTEURS}

\section{ELIE PIETTE}

Université de Liège 